\title{
НОВЫЕ АСПЕКТЫ ПРОБЛЕМЫ РЕГИОНАЛЬНОГО ПРЕДСТАВИТЕЛЬСТВА В БРИТАНСКОЙ ПАЛАТЕ ЛОРДОВ
}

\begin{abstract}
Аннотация: В статье исследуется проблема разработки и реализации на практике масштабной программы конституиионной модернизачии в Великобритании. Центральное внимание уделено двум ее аспектам-передаче части властных полномочий из центра в руки региональных властей в рамках осуществления программы деволючии, а также реформе Палаты лордов. Анализируется комплекс разнообразных причин, вызвавших необходимость внесения корректив в конституиионно-правовой механизм Соединенного королевства, дается оценка отношения кним основных политических партий страны, а также внутрипартийных группировок и течений. Исследуется история представительства от регионов страны в верхней палате британского Парламента. Рассматриваются уже осуществленные преобразования, определяются их позитивные и негативные последствия, выявляются перспективы и направления дальнейшей модернизации механизма государственного управления. Отмечается тесная взаимосвязь и взаимозависимость проводимых преобразований. Растущая регионализация требует формирования новых отношений с центральной властью, делает актуальной проблему пересмотра принципов формирования и полномочий верхней палаты Парламента, вновь ставит в повестку дня проблему коррекции избирательной системы.

Review: The article is devoted to the problem of development and practical implementation of the large scale constitutional modernization program in the Great Britain. Central attention is paid to two of its aspects - transfer of some powers from the center to the regional organs within the devolution program, as well as the reform of the House of Lords. The author analyzes a complex of various causes, which resulted in the need to correct a constitutional legal mechanism of the United Kingdom, he also provides the analysis of attitude of the key political parties, inner groups within such parties and movements to these changes. The author also studies the history of representation of the regions of the state in the higher chamber of the British Parliament, the changes which already took place and the perspectives and directions for the further modernization of the state government mechanism. The close connection and interdependence of the changes is being noted. The growing regionalization demands formation of the new type of relations with the central government, and it makes the problem of revision of principles of formation and powers of the higher chamber of the Parliament especially topical, it also requires correction of an election system. Ключевые слова: Великобритания, конституционные реформы, Палата лордов, деволюиия, регионализаиия, наиионализм, политическая борьба, консерваторы, лейбористы, представительство
\end{abstract}

Keywords: the Great Britain, constitutional reforms, the House of Lords, devolution, regionalization, nationalism, political strife, the Conservators, the Tory, the Labour, representation.

Второй этап регионализации и формирование программы конституционных реформ

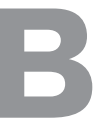
озрождение интереса к проблеме повышения эффективности институтов центрального и местного управления произошло в последнем десятилетии прошлого века и было вызвано целым комплексом причин. Переход от кейнсианских к монетаристским механизмам регулирования социально-экономических процессов, начавшаяся трансформация партийно-политической системы, очередной всплеск националистических на- строений, подпитываемый уже не только внутренними факторами, но и реализуемой в рамках Европейского союза региональной политикой, диктовали объективную необходимость модернизации системы управления страной и коррекции конституционных норм, определяющих ее каркас. Все более очевидным становился тот факт, что не удастся ограничиться обновлением какого-то одного элемента механизма центральной власти, а потребуется комплексная перенастройка всей системы.

Особенную активность в деле разработки соответствующих предложений в этот период времени проявляли 
DOI: 10.7256/1811-9018.2013.8.9238

При цитировании этой статьи сноска на dоі обязательна

\section{Право и политика $8(164) \cdot 2013$}

«новые лейбористы», надеявшиеся на то, что избиратели в самое ближайшее время доверят им мандат на управление страной. В июле 1993 г. достоянием общественности стал доклад Рабочей группы по вопросу избирательной реформы, сформированной Национальным исполкомом Лейбористской партии и работавшей под руководством известного юриста и пожизненного члена Палаты лордов, профессора Раймонда Планта. Эксперты исследовали проблему пересмотра действовавшей мажоритарной избирательной системы относительного большинства и пришла к выводу, что она неразрывно связана с необходимостью реформирования Палаты лордов. В частности в докладе Рабочей группы допускалась возможность перехода к новому принципу формирования верхней палаты Парламента, а именно 320-330 её членов предлагалось избирать на основе региональных списков. Оставшиеся пэры подлежали назначению премьер-министром. ${ }^{1}$

После триумфальной победы на всеобщих парламентских выборах 1997 г., лейбористы в своих планах по проведению конституционных реформ и децентрализации власти опирались не только на собственное внушительное большинство в нижней палате. Они вполне могли рассчитывать и на поддержку 46 депутатов из фракции либеральных демократов, с которой они ещё до выборов самым тесным образом сотрудничали в вопросах разработки возможных вариантов модернизации системы управления страной. Обе партии сумели существенно сблизить свои позиции, в том числе и в отношении предстоящей реформы Палаты лордов. Либеральные демократы, например, в своём предвыборном манифесте прямо заявляли о своём желании «... создать демократическую верхнюю палату». «Мы хотим, - декларировалось в их программном документе, - в течение двух парламентских сессий трансформировать Палату лордов в преимущественно избираемую верхнюю палату с представительством от всех наций и регионов Соединённого Королевства и играющую ключевую роль в рассмотрении европейского законодательства». ${ }^{2}$ Как видно, такой подход был достаточно близок к планам «новых лейбористов», и правительство Т. Блэра не без оснований надеялось на поддержку депутатов от Либерально-демократической партии при голосованиях по вопросу о лишении наследственных пэров права участвовать в заседаниях и голосованиях в Палате лордов.

Кроме того лейбористы продолжали активно использовать наработки близких к ним исследовательских групп и «мозговых трестов». В частности, существенную лепту в разрабатываемый проект конституционных реформ в этот период времени внес экспертный центр «Демос»,

${ }^{1}$ Deadman H. Proposals for Reform of the Composition and Powers of the House of Lords, 1968-1998. L., 1998. P. 45-46.

${ }^{2}$ Make The Difference. The Liberal Democrat Manifesto 1997. L., 1997. P. 40. который позиционировал себя в качестве независимой организации, но в его штате работали в основном сторонники идей «нового лейборизма». В июне 1998 г. его сотрудники Энтони Барнетт и Питер Карти опубликовали монографию «Афинский вариант, радикальная реформа Палаты лордов». В ней они предлагали неординарный рецепт реформы, предусматривавший превращение верхней палаты британского Парламента в максимально демократический, с точки зрения формирования состава, орган государственного управления. Большую часть новых членов верхней палаты предлагалось отбирать при помощи жеребьевки из списков британских избирателей пропорционально численности населения в регионах Соединенного королевства. Кроме этого должна была сохраниться маленькая группа назначаемых пэров, состоящая из высококвалифицированных профессионалов и заслуженных людей. ${ }^{3}$ Аргументируя столь неожиданный принцип отбора пэров, авторы книги выдвигали тезис о том, что «Британии вместо того, чтобы пытаться догнать другие страны, следует в полной мере воспользоваться возникшим в результате начавшейся конституционной реформы шансом и продвигаться вперед, экспериментируя с новыми формами демократии». ${ }^{4}$

Летом и осенью 1998 г. достоянием общественности стали еще несколько оригинальных идей возможной перестройки верхней палаты британского Парламента в контексте нарастающей регионализации и инициированных лейбористским Кабинетом масштабных конституционных преобразований. К примеру, валлийский политический журналист и издатель Джон Осмонд в памфлете «Реформировать лордов и изменить Британию», изданном в августе 1998 г. Фабианским обществом, также увязывал реформу принципов формирования верхней палаты с уже реализованной правительством Т. Блэра программой деволюции. По его мнению, передача части управленческих полномочий органам власти в провинциях Соединенного королевства свидетельствовала о развитии федералистских тенденций, следовательно, и пэры в Палату лордов должны были избираться от составных частей страны, а сама она выступать в качестве представителя региональных и национальных интересов. ${ }^{5}$

Похожие предложения содержались и в проекте, опубликованном спустя месяц известной британской группой давления «Хартия 88», выступавшей за реформу избирательной системы и совершенствование конституционного законодательства. В памфлете «Реформа Палаты лордов» отмечалось, что в меняющихся условиях пэры должны

\footnotetext{
${ }^{3}$ Barnett A., Carty P. The Athenian Option, Radical Reform of the House of Lords. L., 1998. P.7.

${ }^{4}$ Ibid. P. 9.

${ }^{5}$ Osmond J. Reforming the Lords and Changing Britain. L., 1998. P. 29-30.
} 
стать важным связующим звеном между региональными и центральными институтами управления и способствовать укреплению союза всех составных частей королевства. Отмечая, что ликвидация наследственного представительства является назревшей и своевременной мерой, авторы работы подчеркивали необходимость скорейшего определения сроков и базовых принципов следующих этапов реформы. Формировать состав новой палаты они предлагали с использованием пропорциональной системы и настаивали на том, что срок ее полномочий должен отличаться от того, который предусмотрен для Палаты общин. ${ }^{6}$

Значительное внимание в рассматриваемом документе уделялось и функциям пэров. Они должны были обладать правом законодательной инициативы, возможностью контролировать, пересматривать, а в случае необходимости, и задерживать билли, одобренные в нижней палате. Констатируя, что в большинстве случаев Правительство и Оппозиция сосредоточены на вопросах текущего законодательства, авторы данного плана полагали, что Палата лордов сможет больше уделять времени проблемам долгосрочного развития. ${ }^{7}$ Таким образом, уже к концу парламентской сессии 1997-1998 гг. в британском обществе, научных, экспертных и политических кругах активно циркулировали и обсуждались сразу несколько вариантов возможной модернизации верхней палаты Парламента. Лидеры Лейбористской партии не могли пожаловаться на недостаток идей для формулирования конкретного содержания следующих этапов реформы. Но прежде им еще предстояло добиться практического воплощения казалось бы всем очевидного и давно назревшего решения - ликвидации наследственного представительства.

В целом же, следует отметить, что проблема модернизации Палаты лордов во второй половине 1990-х гг. во многом именно благодаря «новым лейбористам» приобрела новые очертания. Прежде всего, следует отметить, что Т. Блэру и его сподвижникам удалось возродить интерес к необходимости превращения ее в современный, демократический и эффективный институт государственного управления, сделать важнейшей составной частью своей программы масштабных конституционных преобразований. Используя богатейший, накопленный за предшествующие годы потенциал различных предложений, лейбористские лидеры задумали комплексную реформу, предусматривающую, в первую очередь, ликвидацию тех принципов формирования состава Палаты лордов, которые наиболее вопиющим образом не соответствовали общественно-политическим реалиям конца ХХ века, в том числе и изменившейся системе взаимоотношений между центром и регионами страны. После этого они

${ }^{6}$ Reform of the House of Lords, September 1998. // URL: http://www. charter88.org.uk/pub/policy/9810_lords_sum.html_(17.03.2012)

${ }^{7}$ Ibidem. планировали предпринять меры по повышению качества работы верхней палаты, определить ее новые функции и полномочия, сформировать наиболее оптимальный вариант взаимодействия с Палатой общин.

Консервативная партия после мая 1997 г., с одной стороны пыталась заблокировать лейбористский вариант конституционной модернизации в целом и реформирования Палаты лордов в частности, а с другой стороны, ее тогдашние лидеры прекрасно понимали, что оставить все как было прежде невозможно, и в новых исторических условиях необходимо срочно предлагать альтернативные проекты преобразований. Уже в ноябре 1997 г. лидер Оппозиции в Палате лордов виконт Крэнборн выступил со специальным заявлением для прессы, в котором отмечал: что любые попытки реформирования верхней палаты Парламента «должны базироваться на шести основополагающих принципах:

1. Перемены не должны привести к усилению полномочий премьер-министра в вопросах назначения новых пожизненных пэров.

2. Состав новой верхней палаты должен отличаться от состава Палаты общин при сохранении за последней безусловного верховенства.

3. В новой палате должна быть сохранена значительная группа независимых пэров, имеющих возможность отстаивать свои взгляды.

4. В составе новой палаты должны быть представители от всех регионов Соединённого Королевства.

5. Планы реформ должны исходить из того, что новая палата будет иметь большие полномочия при рассмотрении и изменении законодательства, нежели прежняя.

6. Палата лордов не может быть реформирована отдельно, перемены должны затронуть обе палаты парламента». ${ }^{8}$

Таким образом, можно констатировать, что своей приоритетной задачей тори считали сохранение как минимум в прежнем объеме или даже укрепление властных полномочий верхней палаты британского Парламента и признавали лишь необходимость некоторой корректировки принципов ее формирования. Примечательным, на наш взгляд является то, что консерваторы также как и их основные политические оппоненты считали необходимым возродить практику регионального представительства в Палате лордов.

Несмотря на то, что реальных возможностей создания непреодолимых преград на пути лейбористского варианта реформирования верхней палаты у Оппозиции не было, она настойчиво пыталась перехватить инициативу. В апреле 1999 г. в разгар обсуждения в Парламенте инициированного Кабинетом Т. Блэра Законопроекта о Палате

\footnotetext{
${ }^{8}$ Deadman H. Proposals for Reform of the Composition and Pow-
} ers... P. 64. 
DOI: $10.7256 / 1811-9018.2013 .8 .9238$

При цитировании этой статьи сноска на dоі обязательна

\section{Право и политика 8 (164) • 2013}

лордов, специально созданная в Консервативной партии Конституционная комиссия представила альтернативный план модернизации Палаты лордов. В опубликованном докладе комиссии ее предлагалось переименовать в Сенат и сделать преимущественно выборной. Сенаторы должны были получать такую же оплату за свой труд, как и депутаты Палаты общин, иметь возможность подавать в отставку и право избираться после этого в нижнюю палату. Срок полномочий сенаторов должен был составить 15 лет, а их общая численность - сократиться до 400-550 человек. ${ }^{9}$

Конституционная комиссия также разработала два варианта формирования новой палаты. Согласно первому из них - 480 сенаторов избирались прямыми выборами в 80 шестимандантных округах (каждые пять лет треть из них подлежала переизбранию - И.К.), еще 45 - назначались премьер-министром для выполнения функций министров, 12 мест отводилось ординарным лордам по апелляциям. ${ }^{10}$ Второй вариант был более сложным. Согласно нему 150 сенаторов отбирались из числа экспертов в различных сферах государственного управления специальной Комиссией по назначениям. Помимо этого, 99 членов новой палаты должны были косвенно избирать представительные органы Шотландии, Уэльса, Северной Ирландии и английских регионов в ходе каждых всеобщих парламентских выборов. Такое же количество сенаторов параллельно избиралось непосредственно гражданами по региональным спискам. Кроме этого 100 человек получали место в Сенате пожизненно, а 12 мест отводилось правовым лордам. ${ }^{11}$

Фактически данный проект тори был нацелен на некоторую демократизацию принципов формирования состава верхней палаты, кроме этого, он предусматривал автоматическую ликвидацию представительства иерархов Церкви Англии, предоставлял возможность выбора между смешанным комплектованием и преимущественно избираемой палатой, по сути предлагал ввести региональное представительство. В интервью газете «Гардиан» председатель Конституционной комиссии барон Маккей Клэшфернский утверждал, что сформулированные предложения укрепят консультативную роль верхней палаты и повысят ее легитимность. «Мы постарались добиться того, - подчеркивал он, - чтобы ее состав отличался от состава Палаты общин, и чтобы ее члены ощущали более высокую степень независимости от партийных машин». ${ }^{12}$ Однако, Кабинет Т. Блэра вполне ожидаемо не обратил никакого внимания на рекомендации торийской Конституционной комиссии и всячески демонстрировал стремление добиться принятия Парламентом собственного билля.

\footnotetext{
${ }^{9}$ Report of the Constitutional Commission on Options for a New Second Chamber. L., 1999. P. 11-14.

${ }^{10}$ Ibid. P. 18-21.

${ }^{11}$ Ibid. P. 22-25.

${ }^{12}$ The Independent 16 April 1999.
}

Консерваторы в связи с этим вынуждены были искать любые, иногда даже самые невероятные варианты блокирования правительственного законопроекта. Примечательно, что неоднократно для этого использовалась и проблема регионального представительства. В частности, 22 июня 1999 г. лорд Грей выступил с предложением отправить обсуждаемый билль на экспертизу в Комитет по привилегиям. С его точки зрения, инициатива Кабинета вступала в противоречие с положением Акта о союзе с Шотландией 1706 г, предоставившим шотландским наследственным пэрам места в Палате лордов. В случае принятия лейбористского законопроекта, указывал он, «Шотландия как равноправная часть Соединенного Королевства будет лишена своего представительства в верхней палате Парламента». ${ }^{13}$ Впрочем, и этот маневр закончился безрезультатно. Комитет по привилегиям, проанализировав текст законопроекта, пришел к заключению, что Акт о союзе с Шотландией 1706 г. не имеет особого статуса и его положения могут меняться любым другим актом Парламента, что неоднократно имело место в британской истории. Следовательно, отмечалось в решении комитета, представленный правительством T. Блэра Законопроект о Палате лордов может содержать статьи об исключении шотландских наследственных пэров наряду с английскими потомственными членами верхней палаты Парламента. ${ }^{14}$

Как известно, лейбористам в итоге удалось добиться принятия Акта о Палате лордов 1999 г., который лишил возможности заседать в верхней палате британского Парламента представителей наследственной титулованной знати и стал важнейшим шагом в направлении коренной модернизации принципов формирования законодательной власти в Великобритании. Однако, вопрос о начале, а самое главное о конкретном содержании, второго этапа обещанной еще в конце прошлого века комплексной реформы Палаты лордов так и оставался открытым. Правящая Лейбористская партия никак не могла определиться с тем, чего же конкретно она хочет. За первое десятилетие XXI века по этому вопросу было издано две белых книги, организовано несколько внутрипартийных, а также межпартийных дискуссий и консультаций. Дважды проводились голосования в обеих палатах Парламента для выяснения того, какой из множества вариантов формирования состава новой Палаты лордов представляется более предпочтительным, давались обещания вынести проблему дальнейшей реформы на общенациональный референдум и т.д. Однако, все это закончилось практически ничем. Реальных шагов и законодательных предложений в рамках второго этапа комплексной модернизации так и не было сделано.

\footnotetext{
${ }^{13}$ Great Britain. Parliamentary Debates. House of Lords. Fifth Series. Vol. 602. Col. 873-875.

${ }^{14}$ Second Report from the Committee for Privileges // URL: htt://www. parliament.the-stationery-office.co.uk (17.03.2012)
} 


\section{Трансформация правовых и политических систем}

Параллельно с этим в Соединенном королевстве продолжал развиваться процесс регионализации. Шотландия, Уэльс и Северная Ирландия обрели опыт формирования и функционирования местных легислатур и органов исполнительной власти, произошли заметные сдвиги в отраслевой структуре и динамике хозяйственного развития этих провинций, продолжали усиливаться националистические настроения среди их жителей, местные националистические партии существенно укрепили свои позиции в регионах. В 2007 г. Шотландская национальная партия сумела добиться права сформировать исполнительную власть в провинции и стала активно добиваться проведения референдума о выходе Шотландии из состава Соединенного королевства.

\section{Отложенная модернизация}

Принципиально новая общественно-политическая ситуация сложилась в Великобритании после всеобщих парламентских выборов в мае 2010 г. и формирования коалиционного Правительства Дэвида Кэмерона. Стоит напомнить, что обещание провести назревшие конституционные преобразования, в частности реформировать Палату лордов, содержались в предвыборных манифестах всех трех ведущих партий Великобритании. Объективно этот факт должен был способствовать быстрой выработке соответствующих законодательных предложений и проведению их через Парламент. Сложность заключалась только в том, насколько быстро руководители фракций смогут преодолеть существовавшие между ними разногласия относительно целей и масштабов преобразований. Консерваторы, заключив соглашение с либеральными демократами, не могли не учитывать их давнюю и широко известную приверженность идеям федерализации. С другой стороны, тори, очевидно, не были удовлетворены итогами деволюции и стремились усилить позиции центральной власти во взаимоотношениях с региональными органами управления. В частности, уже в июне 2010 г. Правительство Д. Кэмерона, формально в связи с необходимостью экономии бюджетных средств в условиях экономического кризиса, объявило о ликвидации к 2012 г. сформированных при лейбористах Агентств регионального развития и передаче их функций в ведение местных бизнес-партнерств. ${ }^{15}$ Вместе с тем, лидеры консерваторов прекрасно понимали, что полная ревизия расширения круга полномочий властей в исторических провинциях страны невозможна, и им необходимо с учетом новых реалий перестраивать взаимоотношений между центром и регионами.

\footnotetext{
${ }^{15}$ Supporting economic growth through local enterprise partnerships. // URL: https:/www.gov.uk/government/news/councils-and-businessesto-rebalance-local-economy $(09.07 .2013)$
}

Политическим лидерам в непростых условиях «подвешенного» Парламента пришлось идти на вынужденные взаимные уступки и компромиссы для выработки согласованной программы действий, необходимых для эффективного разрешения целого ряда непростых социально-экономических, конституционно-правовых и политических проблем. В обмен на согласие с планами консерваторов по сокращению бюджетных расходов и реформированию здравоохранения и высшего образования, либеральные демократы настояли на включение в план действий Кабинета целого ряда конституционных реформ. В их числе оказались проведение референдума по переходу к преференциальной системе голосования на всеобщих парламентских выборах и намерение реформирования Палаты лордов, причем с учетом возросшей автономизации исторических провинций королевства. В программе, сформированной двумя партиями коалиции, в частности говорилось следующее: «Мы создадим комитет для подготовки предложений о полностью или частично избираемой верхней палате на основе пропорционального представительства... В переходный период, назначение новых пэров будет осуществляться с учетом распределения голосов между политическими партиями на последних всеобщих выборах». ${ }^{16}$

Фактически вместо всеобъемлющего, многоступенчатого и во многом спорного проекта разработанного в конце XX в. «новыми лейбористами», Правительство Д. Кэмерона предложило вернуться к идее очередной коррекции принципов формирования состава новой второй палаты британского Парламента. Менее чем через год после прихода к власти, ему удалось подготовить проект Билля о реформе Палаты лордов, который был представлен на суд общественности 17 мая 2011 г. Основные новации в этом документе сводились к следующему:

- Общая численность новой Палаты лордов будет сокращена до 300 человек, 80\% из которых будут избираться, а оставшиеся $20 \%$ - назначаться монархом из числа экспертов в разных областях знаний.

- Новые члены будут избираться поэтапно. Начиная с 2015 г., каждые 5 лет будет избираться треть состава палаты. Срок полномочий избранных членов - 15 лет, без права повторного переизбрания.

- Выборы будут проводиться по пропорциональной избирательной системе в многомандатных округах, сформированных на основе административно-территориального деления страны.

- Выборы новых членов Палаты лордов будут проводиться в те же сроки, что и всеобщие парламентские выборы.

\footnotetext{
${ }^{16}$ The Coalition: Our Programme for Government. L., 2010. P. 27.
} 


\section{Право и политика $8(164) \cdot 2013$}

- $\quad$ Пэрские титулы останутся знаком почести и утратят непосредственную связь с членством в верхней палате Парламента

- $\quad$ Численность духовных лордов будет сокращена с 26 до 12 человек.

- $\quad$ Функции и полномочия Палаты лордов на этом этапе останутся прежними.

- Проект билля и соответствующая белая книга будут переданы в специальный совместный комитет палат Парламента для более детальной разработки и подготовки рекомендаций. ${ }^{17}$

Подобные меры должны были привести к существенному изменению места и роли британской верхней палаты в системе законодательной власти страны. Она становилась бы преимущественно избираемой, причем по системе отличной от той, которая применяется при формировании состава депутатов Палаты общин, членство в Палате лордов не связывалось бы более с обладанием аристократическим, пусть и пожизненным титулом, а сама она фактически превратилась бы в институт, представляющий в законотворческом органе интересы регионов Соединенного королевства.

Наиболее последовательными сторонниками принятия подобных изменений были либеральные демократы, которые всеми силами стремились доказать своим избирателям, что они равноправные участники коалиции и их уступки тори в социально-экономических вопросах в должной мере компенсируются реальными шагами в области конституционных преобразований. Кроме того, они демонстрировали, что несмотря на то, что граждане Великобритании отвергли их идею о переходе к преференциальной системе голосования при формировании Палаты общин на общенациональном референдуме 5 мая 2011 г., партия будет продолжать добиваться проведения модернизации системы центрального управления. Выступая во время официального представления законопроекта коалиционного Кабинета, заместитель премьер-министра и лидер либеральных демократов Ник Клегг особенно подчеркивал решительные намерения своих коллег по этому вопросу, противопоставив их сомнениям и осторожности лейбористов: «Правительства и политики, представлявшие разные партии, говорили о реформе Палаты лордов на протяжении более века, и сейчас мы намерены завершить этот процесс». ${ }^{18}$

Необходимость предпринятого шага формально признавали и лидеры тори. «Палата лордов и ее члены, - подчеркнул в своем выступлении премьер-министр

${ }^{17}$ House of Lords Reform Draft Bill. L., 2011. P. 7-9.

${ }^{18}$ Proposals for a Reformed House of Lords Published // URL: http://www.dpm.cabinetoffice.gov.uk/news/proposals-reformedhouse-lords-published (17.03.2012)
Д. Кэмерон, - замечательно работали для страны. Тем не менее, реформа Палаты лордов стояла в повестке дня более ста лет, и многие правительства рассматривали комплекс вопросов, которые с ней связаны, но всеобъемлющая реформа до сих пор не реализована». ${ }^{19}$ Вместе с тем, они были вынуждены учитывать, то очевидное обстоятельство, что по этому вопросу в рядах консерваторов не было единства, и значительная часть парламентской фракции была против проекта, сформированного под давлением младшего партнера по коалиции. Многие депутаты-тори указывали на то, что тратить силы и время на обсуждение неоднозначного конституционного вопроса в условиях, когда необходимо решать сложные социально-экономические проблемы и преодолевать последствия мирового финансового кризиса - это непозволительная роскошь.

Первые сомнения в том, что реформа будет реализована в том виде, в каком ее представило коалиционное правительство, возникли уже в ходе обсуждения проекта в рамках совместного комитета. Он был сформирован 23 июня 2011 г. и состоял из 26 человек: 13 пэров и 13 депутатов Палаты общин. В итоговом докладе этого совместного комитета, опубликованном 23 апреля 2012 г., правительственная концепция была одобрена в целом, хотя в нее и были внесены некоторые коррективы. В частности, Кабинету было рекомендовано провести общенациональный референдум по вопросу о реформе Палаты лордов. ${ }^{20}$ Вместе с тем, 12 членов комитета, шесть из которых представляли Консервативную партию, также подписали документ под названием «Реформа Палаты лордов: альтернативный путь», что свидетельствовало об отсутствии консенсуса между палатами парламента и различными политическими силами страны по этому вопросу. ${ }^{21}$

Лидеры коалиции - Д. Кэмерон и Н. Клегг после публикации доклада совместного комитета дружно демонстрировали намерение завершить начатое дело и поставили под сомнение необходимость проведения референдума, поскольку он, без сомнения, как минимум отложил бы принятие соответствующего законопроекта еще на какое-то время, а возможно и вовсе перечеркнул бы планы правящего Кабинета. ${ }^{22}$ Однако, по свидетельству министра юстиции и

\footnotetext{
${ }^{19}$ Ibidem.

${ }^{20}$ Report of the Joint Committee on the Draft House of Lords Reform Bill // URL: http://www.parliament.uk/business/committees/ committees-a-z/former-committees/joint-select/draft-house-of-lordsreform-bill/news/publication-of-report/ (11.07.2013)

${ }^{21}$ House of Lords Reform: an Alternative Way Forward, a report by members of the Joint Committee of both Houses of Parliament on the Government's Draft House of Lords Reform Bill, April 2012, accessed 1 May 2012 // URL: www.parliament.uk/briefing-papers/RP12-37. $\operatorname{pdf}(05.07 .2013)$

${ }^{22}$ Nick Clegg sceptical on Lords reform referendum // URL: http://
} 
лорд-канцлера К. Кларка многие члены фракции консерваторов в Палате общин были против новых предложений, а шесть членов Кабинета и вовсе выступили против любых нововведений в отношении Палаты лордов. ${ }^{23}$ Раскол в Консервативной партии по этому вопросу становился все более очевидным и не мог не тревожить лидеров тори накануне внесения законопроекта для обсуждения в Палате общин.

Тем не менее, Билль о реформе Палаты лордов, при вполне благосклонном к нему отношении со стороны лейбористов, внешне без особых проблем достиг стадии второго чтения, а Ник Клегг даже внес в Палате общин предложение об ограничении дальнейшего его обсуждения 10 днями. ${ }^{24}$ Это решение вызвало негодование, как у Оппозиции, так и той части фракции тори, которая была настроена решительно против правительственного плана модернизации. Все громче становились голоса тех депутатов, которые обвиняли Кабинет в поспешности и стремлении провести преобразования без должного всестороннего обсуждения всех деталей. В итоге, 10 июля 2012 г. билль был одобрен во втором чтении 462 голосами против 124, но среди высказавшихся «против» помимо депутатов от Лейбористской партии оказались 92 консерватора, демонстративно нарушивших принцип партийного голосования. ${ }^{25}$ Один из лидеров взбунтовавшихся торийских заднескамеечников и бывший директор банка БарклэйсДж. Норман заявил: «Билль обречен. Вопрос только в том, как быстро Правительство осознает это». ${ }^{26}$ По его мнению, вместо реформирования Палаты лордов, коалиционному Кабинету следовало бы сконцентрироваться на решении наиболее острых социально-экономических проблем. ${ }^{27}$

Столкнувшись со столь серьезным выражением недовольства в рядах собственной партии, Д. Кэмерон вынужден был предпринять меры по сглаживанию конфликта, скорейшему восстановлению партийного единства и фракционной дисциплины. Прежде всего, им было объявлено об отказе от предложения, предусматривавшего ограничение обсуждения билля 10 днями. ${ }^{28}$ Затем премьер-министр провел несколько встреч с членами Правительства и фракции и 3 августа 2012 г.

www.bbc.co.uk/news/uk-politics-17774183 (04.07.2013); House of Lords should be $80 \%$ elected - MPs and peers' report // URL: http:// www.bbc.co.uk/news/uk-politics-17809945 (04.07.2013).

${ }^{23}$ Roberts $O$. Wales and the Reform of the House of Lords. Cardiff 2012. P. 5.

${ }^{24}$ Great Britain. Parliamentary Debates. House of Commons. Sixth Series. Vol. 548. Col. 24.

${ }^{25}$ Great Britain. Parliamentary Debates. House of Commons. Sixth Series. Vol. 548. Col. 274.

${ }^{26}$ The Telegraph 10 July 2012

${ }^{27}$ Ibid.

${ }^{28}$ Great Britain. Parliamentary Debates. House of Commons. Sixth Series. Vol. 548. Col. 188. принял решение и вовсе отложить проведение реформы Палаты лордов до лучших времен. Официальное заявление о снятии правительственного билля с обсуждения в рамках текущей сессии было сделано 3 сентября 2012 г. в первый же день работы Палаты общин после окончания летних каникул. ${ }^{29}$ В очередной раз попытка модернизации и существенной демократизации одного из старейших государственных институтов Соединенного королевства потерпела неудачу.

Почему же столь назревшая реформа, необходимость которой признают все основные политические силы страны, возможные направления и последствия которой неоднократно обсуждали партийные лидеры, депутаты, представители экспертных сообществ, продвигается столь медленно и с таким трудом? Представляется, что причинами этого является целый комплекс факторов. Вопервых, конституционные преобразования по понятным причинам очень ответственное дело, ошибка в котором может дорого стоить. Поэтому британцы в таких вопросах предпочитают действовать осторожно и постепенно обновлять только те элементы системы центрального государственного управления, которые перестали соответствовать текущим реалиям. Немалую опасность может представлять и возможность развития ситуации по «принципу домино», когда коррекция одних составных частей системы по цепной реакции потребует изменения слишком большого количества других институтов.

Во-вторых, в случае с реформированием Палаты лордов можно утверждать, что несмотря на более чем столетний поиск наиболее оптимального варианта модернизации, большинство из возникающих сложных вопросов, связанных с ней, так и не удалось снять. Например, если в ней будут заседать избранные и назначенные пэры, то они, бесспорно, будут обладать разной степени легитимности. Даже если палаты Парламента будут формироваться по разным избирательным системам, политические партии, вне всякого сомнения, сохранят за собой решающую роль в этом процессе, а это приведет к повышению зависимости членов верхней палаты от руководящего партийного аппарата. Необходимость борьбы за электорат вызовет необходимость давать британским избирателям не всегда выполнимые обещания. Даже частично выборная Палата лордов, как представляется большинству аналитиков, сможет претендовать на пересмотр своей нынешней подчиненной роли в законотворческом процессе и т.д.

В-третьих, нужно иметь в виду, что в отношении целей и способов модернизации верхней палаты британского Парламента имеются существенные разногласия не только между ведущими политическими партиями

\footnotetext{
${ }^{29}$ Ibid. Vol.549. Col. 35
} 
DOI: $10.7256 / 1811-9018.2013 .8 .9238$

При цитировании этой статьи сноска на dоі обязательна

\section{Право и политика $8(164) \cdot 2013$}

страны, но и внутри них, особенно среди консерваторов и лейбористов. Эта проблема за последние годы не раз уже становилась причиной возникновения конфликтных и даже кризисных ситуаций внутри фракций, заставляла партийных лидеров в итоге отказываться от уже разработанных проектов преобразований.

Возвращаясь к проблеме регионального представительства в Палате лордов, следует отметить, что развитие процесса регионализации, передача части властных полномочий легислатурам и исполнительным властям Шотландии, Уэльса и Северной Ирландии, объективно диктует необходимость их особого представительства в верхней палате Парламента Соединенного королевства. Как отметил в своем выступлении в марте 2012 г. первый министр Уэльса К. Джонс: «Я считаю, что четыре нации Соединенного королевства должны иметь равное представительство в Палате лордов по территориальному принципу». ${ }^{30}$ В качестве примера он привел США, где каждый штат представлен в Конгрессе двумя сенаторами вне зависимости от размеров своей территории и количества жителей. «Я верю, - заключил лейбористский политик, что договоренность в этом ключе могла бы помочь связать воедино четыре нации Соединенного королевства». ${ }^{31}$

В свете последних событий и предстоящего в 2014 г. референдума по вопросу независимости Шотландии, идея представляется назревшей и актуальной. Однако не стоит забывать, что несмотря на существенно возросшие благодаря программе деволюции полномочия властей исторических провинций государства, Великобритания остается унитарным государством, а ее регионы не являются полноценными субъектами федерации. Дальнейшие уступки местным исполнительным и законодательным органам многими сейчас воспринимаются как опасная тенденция, способная вызвать дальнейшую дезинтеграцию страны и поставить под вопрос сохранение территориальной целостности Соединенного королевства.

\section{Библиография:}

1. Barnett A., Carty P. The Athenian Option, Radical Reform of the House of Lords. L., 1998.

2. Deadman H. Proposals for Reform of the Composition and Powers of the House of Lords, 1968-1998. L., 1998.

3. Great Britain. Parliamentary Debates. House of Commons. Sixth Series. Vol. 548.

4. Great Britain. Parliamentary Debates. House of Lords. Fifth Series. Vol. 602.

\footnotetext{
${ }^{30}$ Цит. по: Roberts $O$. Wales and the Reform of... Р. 1.

${ }^{31}$ Цит. по: Ibidem.
}

5. House of Lords Reform: an Alternative Way Forward, a report by members of the Joint Committee of both Houses of Parliament on the Government's Draft House of Lords Reform Bill, April 2012, accessed 1 May 2012 // URL: www.parliament.uk/briefing-papers/RP12-37. pdf (05.07.2013)

6. House of Lords Reform Draft Bill. L., 2011.

7. Make The Difference. The Liberal Democrat Manifesto 1997. L., 1997.

8. Nick Clegg sceptical on Lords reform referendum // URL: http://www.bbc.co.uk/news/uk-politics-17774183 (04.07.2013);

9. Osmond J. Reforming the Lords and Changing Britain. L., 1998.

10. Proposals for a Reformed House of Lords Published //

11. URL: http://www.dpm.cabinetoffice.gov.uk/news/ proposals-reformed-house-lords-published (17.03.2012)

12. Reform of the House of Lords, September 1998. // URL: http://www.charter88.org.uk/pub/policy/9810_lords_sum. html (17.03.2012)

13. Report of the Joint Committee on the Draft House of Lords Reform Bill // URL: http://www.parliament. uk/business/committees/committees-a-z/former-committees/joint-select/draft-house-of-lords-reform-bill/ news/publication-of-report/ (11.07.2013)

14. Report of the Constitutional Commission on Options for a New Second Chamber. L., 1999.

15. Second Report from the Committee for Privileges // URL: htt:/www. parliament.the-stationery-office.co.uk (17.03.2012)

16. Roberts O. Wales and the Reform of the House of Lords. Cardiff 2012.

17. Supporting economic growth through local enterprise partnerships. // URL: https://www.gov.uk/government/ news/councils-and-businesses-to-rebalance-localeconomy (09.07.2013)

18. The Coalition: Our Programme for Government. L., 2010. P. 27.

19. The Independent 16 April 1999.

20. The Telegraph 10 July 2012

\section{References (transliteration):}

1. Barnett A., Carty P. The Athenian Option, Radical Reform of the House of Lords. L., 1998.

2. Deadman H. Proposals for Reform of the Composition and Powers of the House of Lords, 1968-1998. L., 1998.

3. Nick Clegg sceptical on Lords reform referendum // URL: http://www.bbc.co.uk/news/uk-politics-17774183 (04.07.2013);

4. Osmond J. Reforming the Lords and Changing Britain. L., 1998.

5. Roberts O. Wales and the Reform of the House of Lords. Cardiff 2012. 